\title{
ANATOMIA DO LENHO DE PLINIA TRUNCIFLORA (O. BERG) KAUSEL (MYRTACEAE) ${ }^{1}$
}

\author{
JOSÉ NEWTON CARDOSO MARCHIORI² SIDINEI RODRIGUES DOS SANTOS ${ }^{3}$
}

\begin{abstract}
RESUMO
É anatomicamente descrita a madeira de Plinia trunciflora (O. Berg) Kausel, com base em material proveniente do Rio Grande do Sul. Foram observados: porosidade difusa; poros muito numerosos e solitários; elementos vasculares de comprimento médio; placas de perfuração simples; pontoações intervasculares alternas e ornamentadas; parênquima apotraqueal difuso-em-agregados; raios heterogêneos, estreitos; fibras de comprimento médio, com pontoações areoladas; e ausência de espessamentos espiralados. Do ponto de vista taxonômico, salienta-se a presença de séries cristalíferas em células não distendidas do parênquima axial.

Palavras-chave: Plinia trunciflora, jaboticabeira, anatomia da madeira, Myrtaceae.

\section{ABSTRACT}

[Wood anatomy of Plinia trunciflora (O. Berg) Kausel (Myrtaceae)].

The wood anatomy of Plinia trunciflora (O. Berg) Kausel is described, based on samples from Rio Grande do Sul state, Brazil. The following features were observed: diffuse porosity; solitary, very numerous and medium size vessel elements; simple perforation plates; alternate vestured pits; diffuse-in-aggregates apotracheal parenchyma; narrow and heterogeneous rays; medium size fibres, with bordered pits; and spiral thickenings, lacking. From the taxonomic point of view, must be emphasized the presence of crystalliferous strands in non-enlarged cells.
\end{abstract}

Key words: Plinia trunciflora, wood anatomy, Myrtaceae.

\section{INTRODUÇÃO}

Frutífera bastante conhecida e largamente cultivada em pomares domésticos, Plinia trunciflora (O. Berg) Kausel, a popular jabuticabeira, é uma das Mirtáceas nativas mais valorizadas no sul do Brasil, notadamente pelos frutos, pequenas bagas de casca negra e polpa branca aderida à semente, muito apreciadas in natura ou para a fabricação de geléias, sucos e licores (Danner et al., 2006).

${ }^{1}$ Recebido para publicação em 05/11/2009 e aceito para publicação em 13/01/2010.

${ }^{2}$ Engenheiro Florestal, Dr., bolsista de Produtividade em Pesquisa ( $\mathrm{CNPq}$ - Brasil), Professor Titular do Departamento de Ciências Florestais, Universidade Federal de Santa Maria. Santa Maria, RS, Brasil. balduinia@mail.ufsm.br

${ }^{3}$ Biólogo, bolsista (CNPq - Brasil), doutorando do Programa de Pós-Graduação em Engenharia Florestal, Departamento de Ciências Florestais, Universidade Federal de Santa Maria. CEP 97105-900. Santa Maria, RS, Brasil. sthurt.bio@gmail.com
Plinia trunciflora é árvore de porte médio (até 15 metros), de casca lisa exfoliante e folhas simples, opostas, lanceoladas, providas de pecíolo e um par de nervuras marginais evidentes (Sobral, 2003). Além destes aspectos, são especialmente notórias, na sua morfologia externa, a caulifloria e a nodosidade do tronco (Marchiori \& Sobral, 1997). De ampla distribuição natural, a jaboticabeira é nativa na $\mathrm{Ar}$ gentina, Bolívia, Paraguai, Peru e Brasil, de Minas Gerais ao Rio Grande do Sul, integrando, neste Estado, a Floresta Estacional do Alto Uruguai e as matas com Araucária (Sobral, 2003).

Ainda desconhecida, sob o ponto de vista anatômico, a jaboticabeira fornece madeira moderadamente pesada, compacta, dura e resistente, indicada para tabuados, móveis e construção civil (Lorenzi, 1992). O presente estudo, ao descrever a anatomia de Plinia trunciflora, pretende contribuir ao conhecimento estrutural 
das madeiras de Mirtáceas Mirtoídeas, nativas no Rio Grande do Sul.

\section{REVISÃO DE LITERATURA}

São escassas as informações anatômicas sobre as espécies nativas do gênero Plinia, inclusive em obras mais abrangentes, como as de Record \& Hess (1949) e Metcalfe \& Chalk (1972).

Em estudo de Plinia martinellii, Barros \& Callado (1997) destacam, entre outros aspectos: porosidade difusa; poros solitários e em múltiplos radiais de 2-4; elementos vasculares de comprimento médio $(755 \mu \mathrm{m})$; placas de perfuração simples; pontoações alternas e ornamentadas; fibrotraqueídeos de comprimento médio $(1170 \mu \mathrm{m})$; parênquima apotraqueal difuso-em-agregados, com tendência a formar faixas irregulares, em séries de 4-14 células; raios heterogêneos (1-3 células de largura); e séries cristalíferas presentes no parênquima axial e nos raios.

Para Plinia rivularis, Denardi et al. (2005) relacionaram os seguintes aspectos anatômicos: porosidade difusa; poros solitários e em múltiplos radiais; elementos vasculares de comprimento médio $(545 \mu \mathrm{m})$; placas de perfuração simples; pontoações alternas; ausência de espessamentos espiralados; fibras de comprimento médio $(1170 \mu \mathrm{m})$, com pontoações areoladas; parênquima axial apotraqueal difusoem-agregados; raios heterogêneos; presença de séries cristalíferas no parênquima axial; e ausência de traqueídeos. Não constam referências sobre ornamentações no pontoado intervascular.

Para o conjunto das Mirtoídeas sul-riograndenses, destacam-se as contribuições de: Marchiori (1984a,b,c; 1987; 1988; 1998), Marchiori \& Muniz (1987), Marchiori \& Brum (1997), Marchiori et al. (2008) e Denardi \& Marchiori (2005).

\section{MATERIAL E MÉTODOS}

O material em estudo, coletado no município de Jaguari (RS), corresponde a uma amos- tra de madeira e respectivo material botânico, incorporados à Xiloteca e Herbário do Departamento de Ciências Florestais (HDCF), da Universidade Federal de Santa Maria, sob o número 3141.

Do material lenhoso, foram extraídos três corpos de prova $(1 \times 2 \times 3 \mathrm{~cm})$ da parte mais externa do lenho, próxima ao câmbio, orientados para obtenção de cortes nos planos transversal, longitudinal radial e longitudinal tangencial. Outro bloquinho foi também retirado, com vistas à maceração.

Os corpos de prova foram amolecidos por fervura em água e seccionados em micrótomo de deslizamento, regulado para a obtenção de cortes com espessura nominal de $20 \mu \mathrm{m}$. Usouse coloração com acridina-vermelha, crisoidina e azul-de-astra (Dujardin, 1964), desidratação em série alcoólica-ascendente $(30 \%, 50 \%, 70 \%$, 95\% e duas vezes em álcool absoluto), diafanização em xilol e montagem de lâminas permanentes, com Entellan.

Para as lâminas de macerado, seguiu-se o método de Jeffrey (Burger \& Richter, 1991); na coloração, usou-se safranina $1 \%$ e, na montagem de lâminas, a mesma resina anteriormente referida.

A descrição microscópica da madeira baseou-se nas recomendações do IAWA Committee (1989). No caso da percentagem dos tecidos, foram realizadas 600 determinações ao acaso, com auxílio de contador de laboratório, conforme proposto por Marchiori (1980). A frequiência de poros foi obtida de forma indireta, a partir de um quadrado de área conhecida superposto a fotomicrografias de seções transversais da madeira. As medições foram realizadas em microscópio Carl Zeiss, com ocular de escala graduada, no Laboratório de Anatomia da Madeira da Universidade Federal de Santa Maria. Nas características quantitativas, os números entre parênteses equivalem aos valores mínimos e máximos observados; o valor que acompanha a média é o desvio padrão. As fotomicrografias foram tomadas em microscó- 
pio Olympus cx40, equipado com câmera digital Olympus Camedia c3000.

\section{DESCRIÇÃO ANATÔMICA}

Anéis de crescimento: distintos, delimitados por fina camada de fibras radialmente estreitas (Figura 1A).

Vasos: muito numerosos a extremamente numerosos $\left(140 \pm 31,4(94-162)\right.$ poros $\left./ \mathrm{mm}^{2}\right)$, ocupando $15,3 \pm 3,8 \%$ do volume da madeira. Porosidade difusa. Poros exclusivamente solitários, ligeiramente poligonais, muito pequenos $(25,4 \pm 5,9(17,5-38,7) \mu \mathrm{m})$, de paredes finas $(2,5 \pm 0,44(1,8-3,7) \mu \mathrm{m})$ e sem padrão definido de organização (Figura 1A,B). Elementos vasculares de comprimento médio ( $476 \pm 101,1$ $(290-710 \mu \mathrm{m})$, com placas de perfuração simples, geralmente oblíquas, e apêndices geralmente em ambas as extremidades. Pontoações intervasculares alternas, circulares $(4,1 \pm 0,64$ $(3,0-5,1) \mu \mathrm{m})$, com abertura em fenda inclusa, ornamentada, pelo menos em parte dos vasos. Pontoações raio-vasculares com aréolas distintas, semelhantes às intervasculares, embora menores $(3,0 \pm 0,32(2,5-3,0) \mu \mathrm{m})$ e restritas às margens de raios. Espessamentos espiralados e conteúdos, ausentes.

Parênquima axial: muito distinto das fibras em corte transversal, representando 21,2 $\pm 3,5 \%$ do volume da madeira; em arranjos apotraqueal difuso e difuso-em-agregados, além de paratraqueal escasso (Figura 1A,B). Séries parenquimáticas geralmente com $4-5(2-8)$ células e 354,7 $\pm 76,8(197,5-487,5) \mu \mathrm{m}$ de altura (Figura 1F). Cristais prismáticos, em séries de até 13 unidades, em câmaras não distendidas do parênquima axial.

Raios: muito numerosos $(19 \pm 1,7(16-22)$ raios $/ \mathrm{mm}$ ), com $1-3$ células de largura (Figura $1 E$ ), ocupando $17,2 \pm 3,1 \%$ do volume da madeira. Raios multisseriados com $180,8 \pm 53,1$ $(100-280) \mu \mathrm{m}$ e $6-21$, mais comumente 9 14 células de altura; heterogêneos, reúnem células procumbentes, na parte multisseriada, e 1 - 2 (4) fileiras marginais de células quadradas, eretas e, por vezes, procumbentes mais altas do que as do corpo central (Figura 1C). A parte multisseriada, é geralmente mais longa do que as margens unisseriadas (Figura 1E,F). Os unisseriados, com 83,2 $\pm 32,7(40-150) \mu \mathrm{m} \mathrm{e}$ 1 - 3 (4) células de altura. Raios axialmente fusionados, frequentes. Células radiais de paredes disjuntas, presentes. Inclusões minerais, células envolventes e células perfuradas, ausentes. Conteúdo de cor escura, pouco abundante.

Fibras: com pontoações areoladas e aberturas cruzadas, presentes nas faces radiais e tangenciais da parede, representando $46,3 \pm 6,3$ $\%$ do volume da madeira. Fibras de comprimento médio $(968,8 \pm 110,2(800-1190) \mu \mathrm{m})$, com $17,6 \pm 1,8(15-21,2) \mu \mathrm{m}$ de largura e paredes finas a espessas $(5,8 \pm 0,89(3,7-7,5) \mu \mathrm{m})(\mathrm{Fi}-$ gura 1B). Fibras septadas, fibras gelatinosas e espessamentos espiralados, ausentes. Traqueídeos vasicêntricos, presentes.

Outros caracteres: variantes cambiais, tubos laticíferos e taniníferos, canais intercelulares, máculas, células oleíferas, células mucilaginosas e estratificação, ausentes.

\section{ANÁLISE DA ESTRUTURA ANATÔMICA}

As características anatômicas descritas para a madeira de Plinia trunciflora estão de acordo com o referido na literatura para as Mirtáceas, por Record \& Hess (1949) e Metcalfe \& Chalk (1972): porosidade difusa; poros muito numerosos, solitários; elementos vasculares de comprimento médio; placas de perfuração simples; pontoações intervasculares alternas e ornamentadas; parênquima apotraqueal difuso-em-agregados; raios heterogêneos, estreitos; e fibras de comprimento médio, com pontoações areoladas. Tais aspectos anatômicos são compartilhados por outras espécies nativas, como: Blepharocalyx salicifolius, Campomanesia guazumaefolia, Myrcianthes gigantea e Myrrhinium loranthoides.

Comparada a Plinia rivularis e a Plinia martinellii, destaca-se, na madeira em estudo, a ausência de poros em múltiplos radiais. Com 

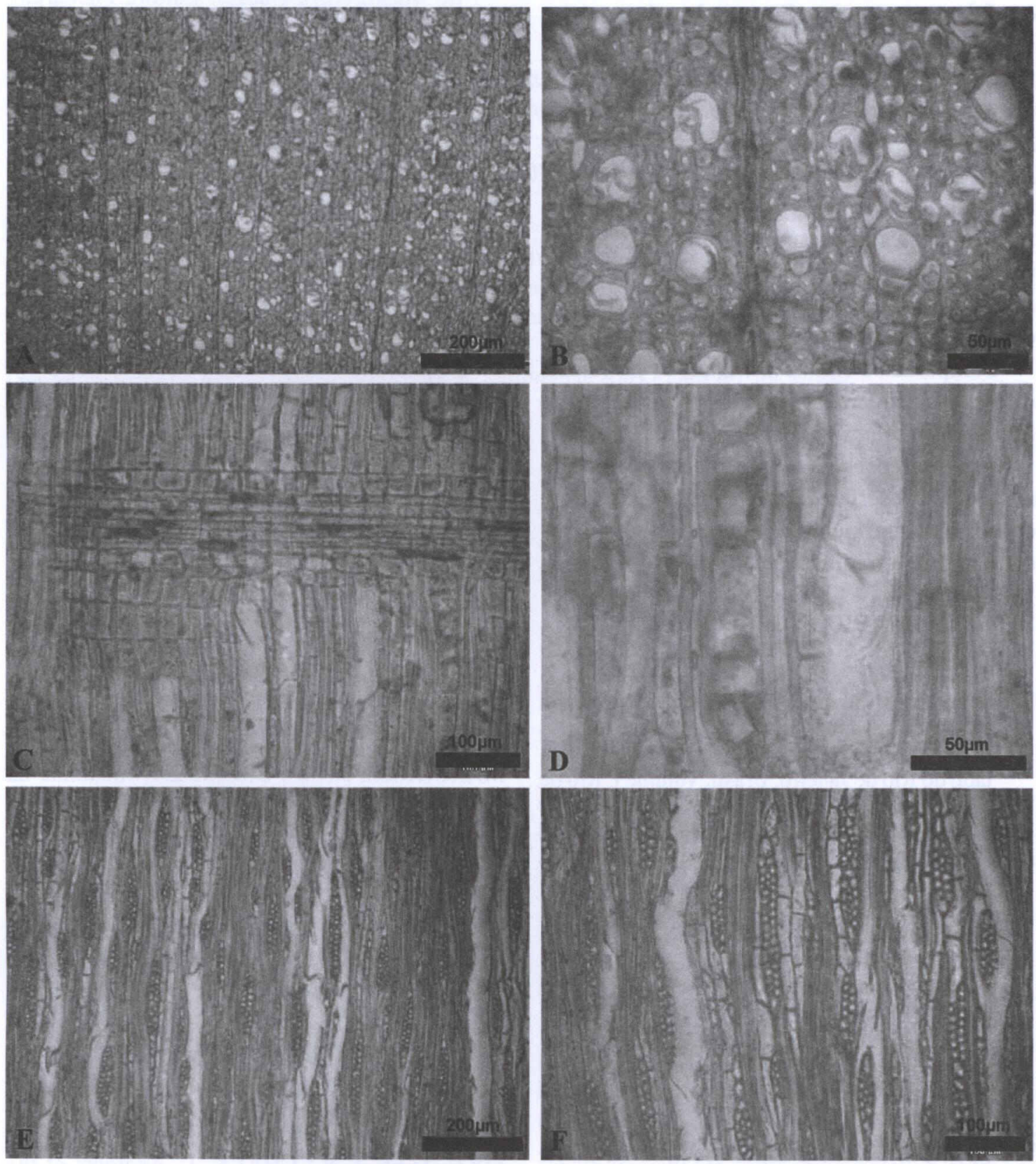

FIGURA 1 - Fotomicrografias da madeira de Plinia trunciflora. A - Porosidade difusa, poros exclusivamente solitários e parênquima apotraqueal difuso e difuso-em-agregados (seção transversal). B - Mesma seção, com maior aumento, destacando-se os parênquimas apotraqueal difuso-em-agregados (seta) e paratraqueal escasso, fibras de paredes finas a espessas, e limite de anel de crescimento (cc). C - Raio heterogêneo, em seção radial, com células procumbentes, no corpo, e margens de células quadradas e, principalmente, eretas. D - Detalhe da seção radial, com cristais em câmaras não distendidas no parênquima axial (seta) e placa de perfuração simples (quadrado). E - Aspecto geral de raios, em seção tangencial. F - Mesma seção, em maior aumento, com destaque para as séries de parênquima axial (seta). 
relação à Plinia martinellii, salienta-se, ainda, a ausência de cristais em raios e de parênquima em faixas tangencias. Comum às três espécies mencionadas, a presença de séries cristalíferas no parênquima axial é também referida para outras Mirtoídeas nativas (Blepharocalyx salicifolius, Eugenia involucrata, Feijoa sellowiana e Myrrhinium loranthoides). Cabe ressaltar, todavia, que as séries cristalíferas, na maioria dos casos, ocorrem em idioblastos, ao passo que na espécie em estudo, bem como em Plinia rivularis, os cristais ocorrem em células de tamanho semelhante ao parênquima normal.

Comparada a Plinia rivularis, as principais diferenças residem na frequiência e diâmetro de poros. Com relação à Plinia martinellii, observam-se diferenças no comprimento de fibras e na altura das séries de parênquima axial, bem como no comprimento de elementos vasculares e na largura e frequiência de poros.

\section{REFERÊNCIAS BIBLIOGRÁFICAS}

BURGER, L.M.; RICHTER, H.G. Anatomia da Madeira. São Paulo: Ed. Nobel, 1991. 154 p.

BARROS, C.F.; CALLADO, C.H. Madeiras da mata atlântica. Anatomia do lenho de espécies ocorrentes nos remanescentes florestais do estado do Rio de Janeiro, Brasil. Volume I. Rio de Janeiro: Instituto de Pesquisas Jardim Botânico do Rio de Janeiro. 1997. v. 1.86 p.

DANNER, M.A.; CITADIN, I.; FERNANDES JUNIOR, A.A.; ASSMANN, A.P.; MAZARO, S.M.; DONAZZOLO, J.; SASSO, S.A.Z. Enraizamento de jabuticabeira (Plinia trunciflora) por mergulhia aérea. Revista Brasileira de Fruticultura, v. 28, n. 3, p. 530-532, 2006.

DENARDI, L.; MARCHIORI, J.N.C. Anatomia do lenho da murta, Blepharocalyx salicifolius (H.B.K.) Berg. Ciência Florestal, Santa Maria, v. 15 , n. 3, p. 267-274, 2005.

DENARDI, L.; MARCHIORI, J.N.C.; FERREIRA, M.R. Anatomia da madeira de Plinia rivularis (Camb.) Rotman. Balduinia, Santa Maria, n. 3, p. 21-25, 2005.

DUJARDIN, E.P. Eine neue HolzZellulosenfaerbung. Mikrokosmos, n. 53, p. 94, 1964.

IAWA COMMITTEE. IAWA list of microscopic features for hardwood identification. IAWA Bulletin, v.10, n. 3, p. 218-359, 1989.
LORENZI, H. Árvores brasileiras: manual de identificação e cultivo de plantas arbóreas nativas do Brasil. Nova Odessa: Editora Plantarum, 1992, $352 \mathrm{p}$.

MARCHIORI, J.N.C. Estudo anatômico do xilema secundário de algumas espécies dos gêneros Acacia e Mimosa, nativas no Estado do Rio Grande do Sul. 1980. 186f. Dissertação (Mestrado em Engenharia Florestal) - Universidade Federal do Paraná, Curitiba, 1980.

MARCHIORI, J.N.C. Anatomia descritiva da madeira do murtilho Myrrhinium loranthoides (Hook. et Arn.) Burret (Myrtaceae). Revista do Centro de Ciências Rurais, Santa Maria, v. 14, n. 1, p. 43-50, 1984a.

MARCHIORI, J.N.C. Anatomia da madeira de Eugenia involucrata DC. (Myrtaceae). Ciência e Natura, Santa Maria, v. 6, p. 127-136, 1984b.

MARCHIORI, J.N.C. Anatomia descritiva do lenho de Feijoa sellowiana Berg. Ciência e Natura, Santa Maria, v. 6, p. 117-125, 1984c.

MARCHIORI, J.N.C. Anatomia descritiva da madeira de Myrceugenia myrtoides Berg. Ciência e Natura, Santa Maria, v. 9, p. 113-120, 1987.

MARCHIORI, J.N.C. Estudo anatômico da madeira de Myrceugenia glaucescens (Camb.) Legr. et Kaus. Ciência e Natura, Santa Maria, v. 10, p. 105-113, 1988.

MARCHIORI, J.N.C. Estudo anatômico da madeira de sete-capotes, Campomanesia guazumifolia (Camb.) Berg. (Myrtaceae). Ciência Rural, Santa Maria, v. 28, n. 1, p. 47-51, 1998.

MARCHIORI, J.N.C.; BRUM, E.T. Anatomia da madeira do guamirim-facho, Calyptranthes concinna DC. (Myrtaceae). Ciência Rural, Santa Maria, v. 27, n. 2, p. 217-222, 1997.

MARCHIORI, J.N.C.; DENARDI, L.; FERREIRA, M.R. Anatomia da madeira de Myrcianthes gigantea (Legr.) Legr. Balduinia, Santa Maria, n. 12 , p. 27-31, 2008.

MARCHIORI, J.N.C.; MUÑIZ, G.I.B. Estudo anatômico da madeira de Myrciaria tenella (DC.) Berg. Ciência e Natura, Santa Maria, v. 9, p. 87-95, 1987.

MARCHIORI, J.N.C.; SOBRAL, M. Dendrologia das Angiospermas: Myrtales. Santa Maria: Editora UFSM, 1997. 304 p.

METCALFE, C.R.; CHALK, L. Anatomy of the Dicotyledons. Oxford: Clarendon Press, 1972. $1500 \mathrm{p}$.

RECORD, S.J.; HESS, R.W. Timbers of the New World. New Haven: Yale University Press, 1949. $640 \mathrm{p}$.

SOBRAL, M. A família Myrtaceae no Rio Grande do Sul. São Leopoldo: Unisinos, 2003. 215 p. 